\title{
TITLE:
}

\section{Light masking of the circatidal activity rhythm in the mangrove cricket Apteronemobius asahinai}

\section{$\operatorname{AUTHOR}(S)$ :}

Takekata, Hiroki; Goto, Shin G.; Satoh, Aya;

Numata, Hideharu

\section{CITATION:}

Takekata, Hiroki ... [et al]. Light masking of the circatidal activity rhythm in the mangrove cricket Apteronemobius asahinai. Biological Rhythm Research 2013, 45(2): 229-233

\section{ISSUE DATE:}

2013-07-01

URL:

http://hdl.handle.net/2433/198797

\section{RIGHT:}

This is an Accepted Manuscript of an article published by Taylor \& Francis in "Biological Rhythm Research" on $01 \mathrm{Ju}$ 2013, available online: http:/ /www.tandfonline.com/10.1080/09291016.2013.797639: This is not the published version. Please cite only the published version.; この論文は出版社版でありません。引用の際には出版社版をご磼認ご利用くだ さい。 


\section{Light masking of the circatidal activity rhythm in the mangrove cricket Apteronemobius asahinai}

Hiroki Takekata ${ }^{\mathrm{a}}$, Shin G. Goto ${ }^{\mathrm{a}}$, Aya Satoh ${ }^{\mathrm{b}}$, and Hideharu Numata ${ }^{\mathrm{c} *}$

${ }^{a}$ Graduate School of Science, Osaka City University, Osaka, Japan; ${ }^{b}$ Faculty of Science, University of the Ryukyus, Okinawa, Japan; ${ }^{\circ}$ Graduate School of Science, Kyoto University, Kyoto, Japan

*Corresponding author. Email: numata@ethol.zool.kyoto-u.ac.jp 


\title{
Light masking of the circatidal activity rhythm in the mangrove cricket Apteronemobius asahinai
}

\author{
Apteronemobius asahinai shows two rhythms in its locomotor activity. One is the \\ circatidal rhythm, which producs active and inactive phases, and the other is the \\ circadian rhythm, which suppresses the intensity of the activity of the circatidal \\ active phase during the subjective day. In the present study, to reveal whether \\ light suppresses the locomotor activity by masking the circatidal rhythm without \\ interfering with the circadian rhythm, we observed the activity under 23-h light- \\ dark cycles before and after RNA interference of the circadian clock gene period \\ (per RNAi), which disrupts the circadian rhythm but not the circatidal rhythm. \\ Hyperactivity just after lights-on and lights-off was observed both before and \\ after per RNAi. However, the activity levels were suppressed in the photophase \\ as compared to the scotophase before per RNAi, but not suppressed in the \\ photophase after per RNAi. Thus, activity of $A$. asahinai is not directly \\ suppressed by light.
}

Keywords: circadian rhythm; light-dark cycles; period gene; RNAi

\section{Introduction}

Intertidal zones are influenced by tidal flooding and ebbing with a period of approximately $12.4 \mathrm{~h}$, in addition to the 24-h day-night cycles, and intertidal zone dwellers have to adapt their lives to the tidal cycles. Many intertidal organisms show tidal rhythms in their activities, and some of these rhythms persist under constant conditions. These endogenous rhythms are called circatidal rhythms, and have been studied in various species, including several insects (Palmer 1995; Naylor 2010).

The mangrove cricket, Apteronemobius asahinai (Insecta, Orthoptera, Trigonidiidae), inhabits mangrove forests, and forages on the forest floor during low tide and rests during high tide. Under constant darkness (DD), adults of this species show two endogenous rhythms in their locomotor activity simultaneously: One is a circatidal activity rhythm generating active and inactive phases with a free-running 
period of approximately $12.6 \mathrm{~h}$, and the other is a circadian rhythm modifying the circatidal rhythm by inhibiting activity during the subjective day (Satoh et al. 2008). The circatidal and circadian rhythms entrain to periodic inundation and light-dark cycles, respectively (Satoh et al. 2008, 2009), and RNA interference (RNAi) of the circadian clock gene period (per) disrupts the circadian rhythm but not the circatidal rhythm (Takekata et al. 2012). These results suggest that the circatidal and circadian activity rhythms in A. asahinai are controlled by two independent clocks.

The circatidal rhythms respond to stimuli correlated with tide, but diel light-dark cycles also affect the activity predominantly controlled by circatidal rhythms in several species. For instance, light-dark cycles directly suppress the activity in the photophase and the scotophase in the cumacean Dimorphostylis asiatica and the horseshoe crab Limulus polyphemus, respectively (Akiyama 2004; Chabot et al. 2008). Such direct effects are called ‘masking’ (Page 1989). The ecological importance of masking in biological rhythms has recently been demonstrated (e.g. Coverdill et al. 2008; Chiesa et al. 2010; Fernández-Duque et al. 2010). In A. asahinai, however, it is still unclear whether light directly suppresses the activity, although light-dark cycles were shown to modify the activity via entrainment of the circadian rhythm (Satoh et al. 2008, 2009).

In the present study, to examine whether light-dark cycles directly affect the activity of A. asahinai lacking circadian rhythm, we observed the activity pattern before and after per RNAi under light-dark cycles. The results showed that the activity in the photophase was not suppressed after per RNAi, but hyperactivity just after lights-on and lights-off was observed both before and after per RNAi.

\section{Materials and methods}

Adult males of $A$. asahinai were collected from mangrove swamps in Ginoza $\left(26^{\circ} 30^{\prime} \mathrm{N}\right.$, 
$127^{\circ} 59^{\prime}$ E), Okinawa Prefecture, Japan in July-November, 2008 and 2009. The crickets were housed in an activity recording chamber on the day of collection.

Double stranded RNAs (dsRNA) for per (dsper) and for $\beta$-lactamase (dsbla), which provides bacteria with ampicillin resistance, were synthesized using T7 RiboMAX ${ }^{\mathrm{TM}}$ Express Large Scale RNA Production System (Promega) as previously described (Takekata et al. 2012). dsbla was used as a control. The dsRNA was suspended in water and its concentration was adjusted to $0.5 \mu \mathrm{g} / \mu \mathrm{l}$. One microliter of dsRNA solution was injected into the abdomen of crickets anesthetized with $\mathrm{CO}_{2}$ using a glass capillary. Takekata et al. (2012) verified that RNAi is effective for this insect.

Activity recording was performed as described previously (Takekata et al., 2012). Crickets were individually housed in plastic chambers with sufficient supplies of food and water. The interruptions of the infrared beam (EE SPW-321, Omron, Kyoto) set across the chamber were recorded at 6-min intervals on a personal computer.

Lighting schedules were controlled by the same computer as used for activity recording. The recording chambers were set in an incubator kept at $25^{\circ} \mathrm{C}$ and equipped with a $15 \mathrm{~W}$ fluorescent lamp (FL15W, Panasonic, Kadoma) with an irradiance of approximately $1.0-3.5 \mathrm{~W} / \mathrm{m}^{2}$.

Circatidal rhythmicity was determined using chi-square periodogram (Sokolove \& Bushell, 1978). The activity with a clear single peak above the 0.05 confidence level between 12 and $14 \mathrm{~h}$ in the periodogram was judged to be circatidal.

\section{Results}

Locomotor activities were recorded under $11.5 \mathrm{~h}$ light and $11.5 \mathrm{~h}$ darkness (LD 11.5:11.5) for 22 cycles, and crickets were injected with dsper or dsbla during the 12th photophase. We used a light-dark cycle with a period (23 h) different from the double of 
the circatidal period, in order to discriminate the entrained circadian rhythm from two cycles of the circatidal rhythm. Crickets injected with dsbla were more active in the scotophase than in the photophase both before and after injection (Figure 1(a)), and most crickets showed clear circatidal rhythms (Figure 2). After dsper injection, the crickets maintained the circatidal rhythm with no significant change in its period (Figure 2). However, the activity level in the photophase was not notably lower than that in the scotophase (Figure 1(b)).

Figure 3 shows the average daily activity profiles of the crickets under LD 11.5:11.5. In the crickets injected with dsbla, the activity peak occurred after lights-on and lights-off, and the activity level in the scotophase was higher than that in the photophase on average. The ratio of the activity level in the scotophase to that in the photophase was approximately 2 both before and after injection (Figure 4(a)). These features were also observed in the crickets before dsper injection (Figure 3(b)). After dsper injection, although the activity peaks occurred after lights-on and lights-off, the activity level in the photophase increased, and the ratio became approximately 1 , which was significantly lower than that before injection (Figure 4(b)). Thus, after per RNAi, the activity level was not suppressed in the photophase.

\section{Discussion}

Masking is a common feature of daily rhythmicity, and a wide variety of invertebrates show a direct response to light (Page 1989). In the American horseshoe crab $L$. polyphemus, which shows a circatidal rhythm but has no circadian component in its locomotor activity under DD, light-dark cycles mask the circatidal rhythm (Chabot et al. 2008). The per $^{0}$ mutant of the fruit fly Drosophila melanogaster shows arrhythmic activity under DD, but a clear diurnal activity pattern under light-dark cycles, and thus 
masking by light is obvious (Wheeler et al. 1993). In A. asahinai, however, there is no difference in the activity level between the photophase and scotophase after per RNAi. We therefore conclude that the circatidal rhythm of A. asahinai is not directly suppressed by light.

However, masking by light actually exists in this species also, because there were activity peaks just after lights-on and lights-off even after per RNAi. In nature, light intensity changes gradually during dawn and dusk, and therefore it is doubtful that A. asahinai becomes especially active during the crepuscular periods. Further studies under naturally changing light conditions will be necessary to determine the natural activity pattern of $A$. asahinai.

\section{Acknowledgements}

We thank Shuhei Hayaishi for collecting insects and Elizabeth Nakajima for linguistic corrections. This study was supported in part by a Core Stage Backup Research Grant from Kyoto University to HN.

\section{Reference}

Akiyama T. 2004. Entrainment of the circatidal swimming activity rhythm in the cumacean Dimorphostylis asiatica (Crustacea) to 12.5-hour hydrostatic pressure cycles. Zool Sc. 21:29-38.

Chabot CC, Skinner SJ, Watson WH. 2008. Rhythms of locomotion expressed by Limulus polyphemus, the American horseshoe crab: I. Synchronization by artificial tides. Biol Bull. 215:34-45.

Chiesa JJ, Aguzzi J, García JA, Sardà F, de la Iglesia HO. 2010. Light intensity determines temporal niche switching of behavioral activity in deep water Nephrops norvegicus (Crustacea: Decapoda). J Biol Rhythms. 25:277-287.

Coverdill AJ, Bentley GE, Ramenofsky M. 2008. Circadian and masking control of migratory restlessness in Gambel's white-crowned sparrow (Zonotrichia leucophrys gambelii). J Biol Rhythms. 23: 59-68. 
Fernàndez-Duque E, de la Iglesia HO, Erkert HG. 2010. Moonstruck primates: owl monkeys (Aotus) need moonlight for nocturnal activity in their natural environment. PLoS One. 5:e12572.

Naylor E. 2010. Chronobiology of marine organisms. Cambridge: Cambridge University Press.

Page T. 1989. Masking in invertebrates. Chronobiol Int. 6:3-11.

Palmer JD. (1995) The biological rhythms and clocks of intertidal animals. New York: Oxford University Press.

Satoh A, Yoshioka E, Numata H. 2008. Circatidal activity rhythm in the mangrove cricket Apteronemobius asahinai. Biol Lett. 4:233-236.

Satoh A, Yoshioka E, Numata H. 2009. Entrainment of the circatidal activity rhythm of the mangrove cricket, Apteronemobius asahinai, to periodic inundations. Anim Behav. 78:189-194.

Sokolove PG, Bushell WN. 1978. The chi-square periodogram: its utility for analysis of circadian rhythms. J Theor Biol. 72:131-160.

Takekata H, Matsuura Y, Goto SG, Satoh A, Numata H. 2012. RNAi of the circadian clock gene period disrupts the circadian rhythm but not the circatidal rhythm in the mangrove cricket. Biol Lett. 8:488-491.

Wheeler DA, Hamblen-Coyle MJ, Dushay MS, Hall JC. 1993. Behavior in light-dark cycles of Drosophila mutants that are arrhythmic, blind or both. J Biol Rhythms. 8:67-94. 
(a)
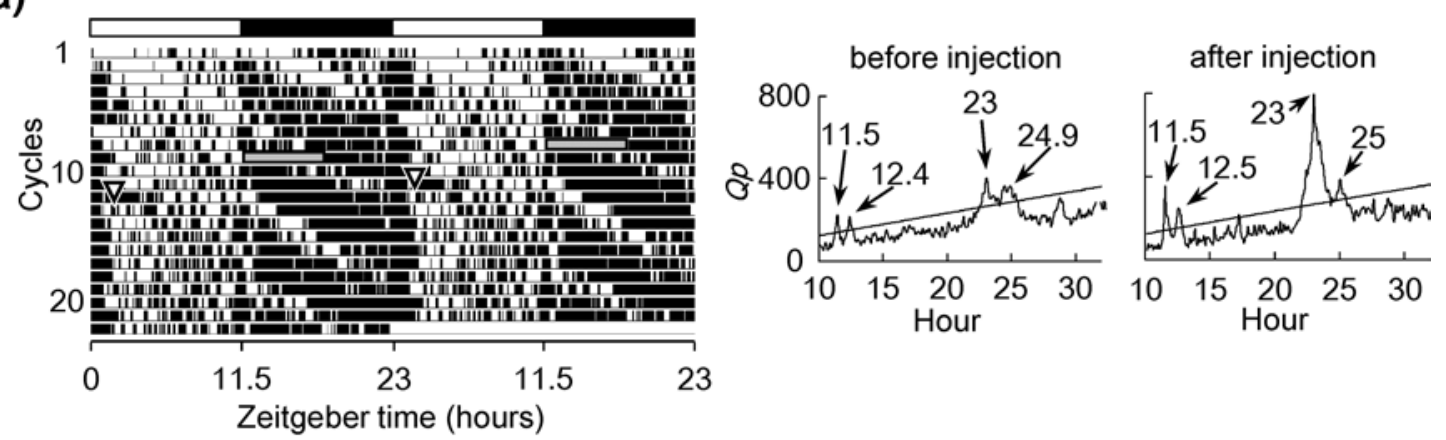

(b)
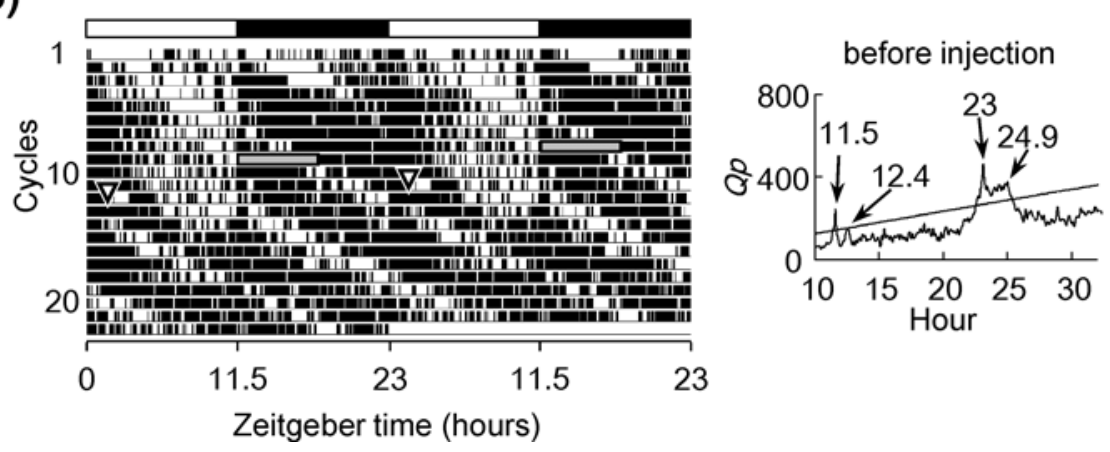

after injection

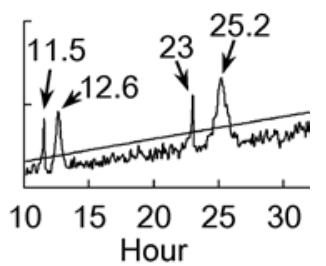

Figure 1. The locomotor activity rhythm presented by double-plotted actograms in adults of Apteronemobius asahinai injected with double-stranded RNA for ß-lactamase (a) and per (b) under 23-h light-dark cycles. At zeitgeber time 2 of the 12th cycle (triangles), crickets were injected with double-stranded RNA. Double-plotted actograms (left) and chi-square periodograms (right) are shown. The abscissae in the actograms show two light-dark cycles with a period of $23 \mathrm{~h}$ (LD 11.5:11.5), and black and white bars above the actograms indicate light and dark phases, respectively. Gray boxes indicate a lack of data. The oblique line in the periodogram indicates the significance level of $\alpha=0.05$ and a peak value above the line is designated as significant 


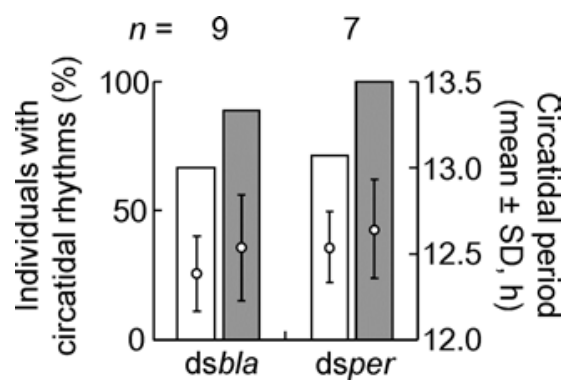

Figure 2. The effect of per RNAi on the circatidal activity rhythms of adults in Apteronemobius asahinai under 23-h light-dark cycles. The proportion of crickets with a circatidal rhythm in the chi-square periodogram (see Figure 1 ) and its period (mean \pm SD) are shown. Crickets were injected with double-stranded RNA for $\beta$-lactamase (dsbla, control), or with double-stranded RNA for per (dsper). White and gray columns indicate the proportions before and after injection, respectively. There is no significant difference in the periods of the circatidal rhythms between the two groups ( $p>0.05$, two-sample $t$-test), and between before and after treatment in each of the groups ( $p>$ 0.05 , paired $t$-test). 

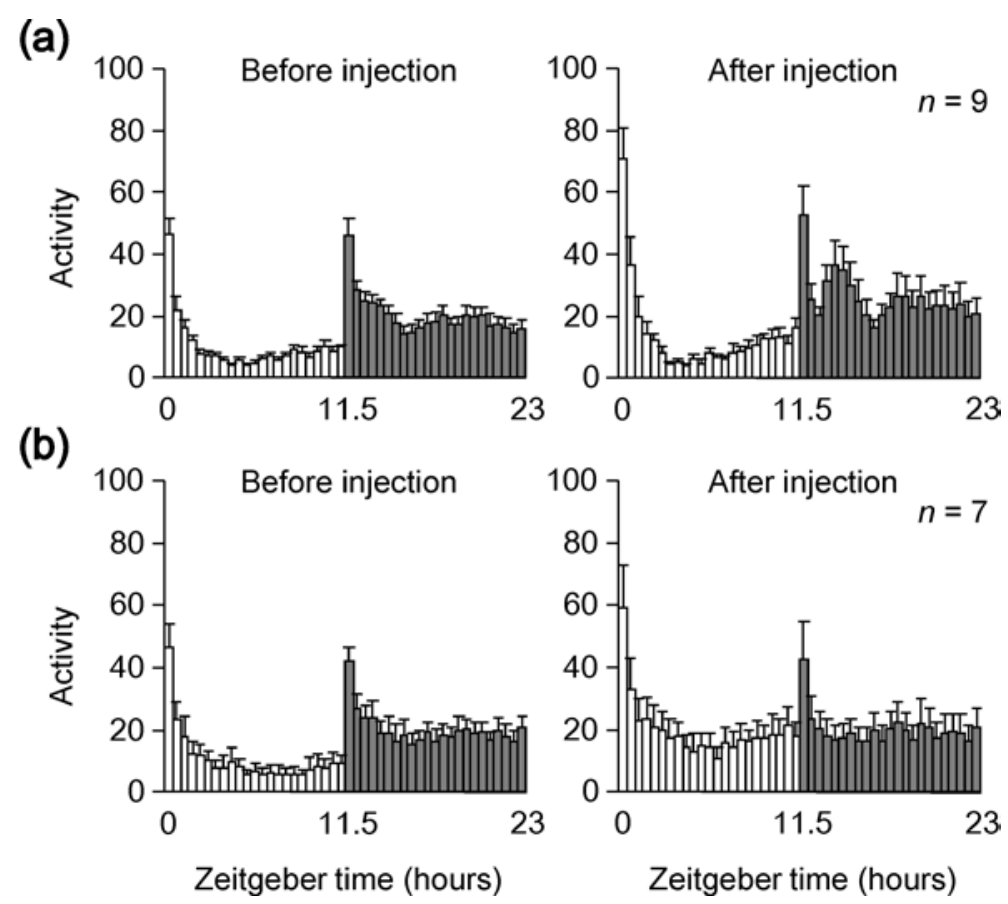

Figure 3. Average daily activity profiles under 23-h light-dark cycles (LD 11.5:11.5) in Apteronemobius asahinai injected with double-stranded RNA for ß-lactamase (a) or for per (b). The locomotor activity was recorded for 22 cycles and crickets were injected at zeitgeber time 2 of the 12th cycle. The numbers of sensed movements per 30 min before and after injection were separately averaged for 10 cycles in each individual, and then the numbers were averaged for all individuals. White and gray columns with vertical bars indicate activity (mean \pm SEM) during the photophase and scotophase, respectively. 
(a)

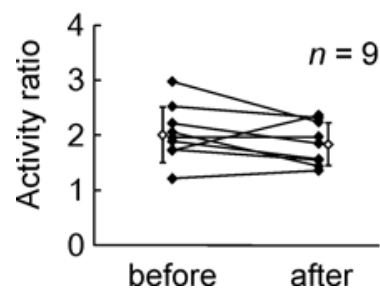

(b)

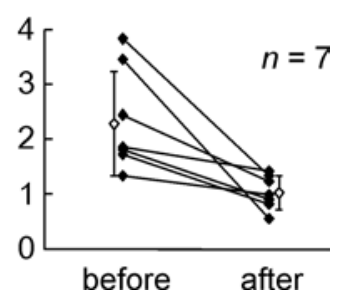

Figure 4. The ratios of the activity level in the scotophase to that in photophase for each individual in Apteronemobius asahinai under 23-h light-dark cycles (LD 11.5:11.5) for 10 cycles before and after injection of double-stranded RNA for ß-lactamase (a) or per (b). The locomotor activity was recorded for 22 cycles and injection was performed at zeitgeber time 2 in the 12th cycle. Black squares indicate the ratios of each individual. White squares and vertical bars indicate averages and SD, respectively. The ratios were not significantly different $(p>0.05)$ and significantly different $(p<0.01)$ between before and after injection of dsbla and dsper, respectively (Wilcoxon signed rank test). 